\title{
Morphological priming without morphological relationship
}

\author{
Catherine-Marie Longtin, Juan Segui, and Pierre A. Hallé \\ Laboratoire de Psychologie Expérimentale, CNRS, Université René \\ Descartes, Boulogne-Billancourt, France
}

\begin{abstract}
Semantic transparency is a crucial factor in the processing of morphologically complex words, but seems to have a different impact depending on experimental conditions and languages. In English, semantic transparency is necessary to produce morphological priming in cross-modal priming, but not as clearly so in masked priming. The available reports of priming effects for opaque prime-target pairs are not as clear-cut as to rule out an explanation in terms of orthographic overlap. Experiment 1 was set out to clarify that issue in French. The novel notion of "pseudo-derivation" we introduce proved useful to show that surface morphology alone can produce priming effects in masked priming. In contrast, pure orthographic overlap produces marginal inhibition. Experiment 2 used auditory-visual cross-modal priming and showed that only semantically transparent words facilitate the recognition of their base.
\end{abstract}

Many studies have attempted to understand the role of morphology in the representation and the processing of multi-morphemic words (for review, see McQueen \& Cutler, 1998). Over the last decade, different factors related to the use and the structure of language have been considered as important in lexical access to morphologically complex words: morpheme productivity (Bertram, Laine, Baayen, Schreuder, \& Hyönä, 2000a; Bertram, Laine, \& Karvinen, 1999), morphology-specific frequencies, such as root or surface frequencies (Burani \& Caramazza,

Requests for reprints should be addressed to Catherine-Marie Longtin, L.P.E., Université René Descartes, 71 Avenue Edouard Vaillant, Boulogne-Billancourt, 92774, Cedex France. Email: longtin@psycho.univ-paris5.fr

This research was supported by a doctoral fellowship to the first author from the Social Sciences and Humanities Research Council of Canada. It was also supported by a "Cognitique" grant (Ministère de la Recherche) and an "Axe d'excellence" subvention from Paris V University. We are grateful to Jonathan Grainger and to an anonymous reviewer for their helpful comments and suggestions on a previous version of this paper.

(C) 2003 Psychology Press Ltd

http://www.tandf.co.uk/journals/pp/01690965.html

DOI: $10.1080 / 01690960244000036$ 
1987; Colé, Beauvillain, \& Segui, 1989; Meunier \& Segui, 1999; Taft, 1979), root and/or affix homonymy (Allen \& Badecker, 1999; Badecker \& Allen, 2002; Bertram et al., 2000a; Bertram, Schreuder, \& Baayen, 2000b; Laudanna, Badecker, \& Caramazza, 1989, 1992), semantic transparency (Boudelaa \& Marslen-Wilson, 2000, 2001; Feldman \& Soltano, 1999; Frost, Forster \& Deutsch, 1997; Marslen-Wilson, Tyler, Waksler, \& Older, 1994; Rastle, Davis, Marslen-Wilson, \& Tyler, 2000). In this paper, we examine the role of two factors in the processing of simple and complex words in French: semantic transparency, and another factor, which we call morphological "pseudo-derivation". We return to this latter factor below.

The notion of semantic transparency refers to how clearly the meanings of a complex word and of the base it is derived from are related. For example, in French, the world fillette "little girl" is semantically related to its base fille "girl", and is thus considered semantically transparent. A word is semantically opaque when its meaning cannot be related to the semantics of its base, although the two words are morphologically related according to etymology. For instance, the word fauvette "warbler" is no longer related to fauve "wildcat", although the latter was derived from the former 800 years ago. Synchronically, whereas fauvette is analysed as a simple word, fillette is perceived as a complex one. Their surface morphological structure is nevertheless the same: both words can be parsed into one base word (fauve or fille) and one productive nominal suffix (-ette).

In an influential paper on English morphology, Marslen-Wilson et al. (1994) showed, using a series of auditory-visual cross-modal priming experiments, that a semantically transparent and morphologically complex word like government primes its base govern, while a semantically opaque word like apartment does not prime its etymological base apart. These authors concluded that semantic transparency is an important factor in the organisation of the lexicon: whereas an opaque word is no longer related to its morphological family, a transparent word is closely linked to it. Thus, an opaque word may be stored as a whole, whereas a transparent word is more likely stored as separate morphemic units.

Later, Frost, Forster, and Deutsch (1997) showed that such a conclusion was not straightforward. Namely, they showed that the role of semantic transparency was not crucial in Hebrew, whose morphology is nonconcatenative. The morphemes of a typical word in Hebrew are intertwined instead of being linearly concatenated as in English or French. Using a masked priming technique, in which the prime is visually presented during $43 \mathrm{~ms}$ and immediately masked by the target (following Forster \& Davis, 1984), the authors reported a priming effect for morphologically related words in Hebrew, irrespective of whether they 
are semantically related. Based on these findings, the authors concluded that neither semantic transparency nor strict morpheme linearity was necessary to obtain morphological priming: two words sharing the same root morpheme seem to be related in the mental lexicon, even if they do not share the same meaning.

Because Marslen-Wilson et al. (1994) and Frost et al. (1997) did not use the same experimental paradigm and the same language, a reasonable question to ask was whether the discrepancy in these findings was due to the different linguistic characteristics of English and Hebrew or to the different experimental procedures used. Recall that the results of MarslenWilson et al. (1994) were obtained with a procedure in which the prime was presented auditorily and thus consciously perceived, while Frost et al. (1997) used a paradigm in which the prime was visually presented for a very short duration and not consciously perceived.

Subsequent studies addressed this particular question and showed that the different findings reflected both linguistic and experimental differences. On the one hand, Frost, Deutsch, Gilboa, Tannenbaum, \& MarslenWilson (2000b) replicated the results of Frost et al. (1997) on Hebrew using cross-modal priming and found a significant priming effect for morphologically related prime-target pairs regardless of whether the semantic relationship was transparent or opaque. However, priming effect was stronger for transparent pairs. Similar results were obtained with Arabic, another Semitic language with non-concatenative morphology (Boudelaa \& Marslen-Wilson, 2000, 2001). On the other hand, Feldman and Soltano (1999) and Rastle et al. (2000) compared the priming effect for English opaque and transparent pairs using a masked priming paradigm (with SOAs of 48 and $43 \mathrm{~ms}$, respectively) and obtained significant priming for both types of derived words. In both Feldman and Soltano's (1999) and Rastle et al.'s (2000) studies, the priming effect observed with opaque pairs disappeared when the SOA was sufficiently increased for the prime to be consciously identifiable $(250 \mathrm{~ms}$ for Feldman and Soltano and $230 \mathrm{~ms}$ for Rastle et al.).

To summarise, there are, on one side, languages such as Hebrew, with non-concatenative morphology, for which morphological relationship is sufficient to produce priming, regardless of semantic transparency and whether the prime is overt (auditory and thus consciously perceived) or covert (visual and subliminal); and on the other side English (and perhaps other languages), with concatenative morphology, for which words that are morphologically but not semantically related prime each other only if the prime is not consciously perceived. It is our belief, however, that the exact nature of the semantic transparency effect in a language like English needs to be studied in more detail. This is because it is unclear whether the priming effect observed with opaque pairs is not 
due to orthographic overlap: indeed, in the Rastle et al. (2000) study, the amounts of priming induced by control orthographic pairs and opaque pairs did not significantly differ. This might be due to the somewhat unclear status of the orthographic control pairs. For some of these pairs, prime and target overlap was purely orthographic, that is, the residual letters did not correspond to a suffix (e.g., cardiac-car); for other pairs, however, the residual letters did form a suffix (e.g., corner-corn:-er is a common suffix of English). The latter pairs may in fact be similar to opaque pairs in that they share no semantic relationship but they are morphologically related at the surface level, and might have been processed as such.

There are therefore reasons to believe that the properties of the stimuli, in particular those of the orthographic controls, play an important role in the ambivalence of the results obtained thus far. The additional notion of pseudo-derivation that we propose in this paper might be useful for a better control of the properties of the materials. By introducing this notion, we hope to shed some light on the effect of the morphological structure in the processing of simple and complex words, using priming techniques.

We thus define a world as morphologically pseudo-derived if it can be parsed into existing morphemes, but is actually neither synchronically nor diachronically composed of these morphemes. For example, in primetarget pairs such as artery/ART, corner/CORN or tailor/TAIL, the target could be morphologically related to the prime, but for some reason it is not. In fact, an artery is not a place where we practice art; neither is a tailor someone who tails. Likewise in French the word baguette could be analysed as bague + -ette (noun + diminutive suffix) since these two morphemes exist in the language. However, this analysis is incorrect because baguette is actually not derived from bague "ring". It means "little stick", "French bread" or "chopsticks", and not "little ring". Moreover, there is no etymological relationship between baguette and bague, and the fact that the latter is phonologically contained within the former is purely accidental. The surface morphemic structure of pseudo-derived words is thus misleading and is not a reflection of their synchronic structure or diachronic formation.

It is important to stress the distinction between pseudo-derived words and pseudo-affixed words, and words containing a pseudo-root. This terminology, as currently used in the literature, applies to words such as cluster in which -er is a pseudo-suffix (cluster is not a derivation of clust) or electrode in which elect is a pseudo-root (electrode is not a derivation of elect). In both cases, when the pseudo-morpheme is removed, the residual letter sequence is not a possible morpheme (either bound or unbound): clust is not a root, and -rode is not a suffix. Burani, Dovetto, Thornton, and 
Laudanna (1997) used these types of words with a naming and lexical decision task. Giraudo and Grainger used words with pseudo-roots or pseudo-affixes as controls for morphological priming (Giraudo \& Grainger 2001 , in press). In contrast, what we call pseudo-derived words are, at the surface level, composed of a pseudo-root and a pseudo-affix, such baguette $=$ bague + -ette.

Our definition of a purely orthographic relationship between two words forming a prime-target pair is the following: The target must be embedded in the prime (so it is a "pseudo-root"), but the remaining letters of the prime must not correspond to an affix of the language. For example, in English the word dialect contains the word dial, but -ect is not a suffix. Similarly, the French word abri "shelter" is included in abricot "apricot", but -cot is not a suffix.

In this research, we wish to assess the role of semantic transparency in French and in particular to establish whether pseudo-derived words are processed in the same way as opaque words or as orthographic controls are, given our more stringent definition of orthographic controls. To address these issues, we conducted two lexical decision experiments to compare the priming effects for transparent, opaque, pseudo-derived, and orthographically related word pairs. Experiment 1 was conducted with a masked priming paradigm (prime duration of $46 \mathrm{~ms}$ ) and Experiment 2 with a cross-modal priming technique. The use of these two techniques allows for a direct comparison with the results reported in the literature. Moreover, these techniques are generally considered to be sensitive to different properties of the prime and the target. While the masked priming technique is sensitive to formal properties of the prime, the cross-modal priming is considered sensitive to semantic and morphological overlap between the prime and the target, but not to orthographic overlap (see Boudelaa \& Marslen-Wilson, 2001; Grainger, Colé, \& Segui, 1991; Marslen-Wilson et al., 1994).

The effect of semantic transparency on the processing of derived words has not been studied extensively in French, whose morphological system is similar, by most account, to English. It is thus likely that we obtain results in French similar to those reported above for English. We also predict that opaque and pseudo-derived pairs will induce similar effects because they share the same formal, morphological, and semantic properties.

\section{EXPERIMENT 1: VISUAL MASKED PRIMING}

\section{Method}

Stimuli and design. We initially selected 30 pairs of words for each of the four following types of relationship: semantically (1) transparent and 
(2) opaque morphological relationship, (3) pseudo-derivation (see the Introduction section), and (4) orthographic overlap. We use "transparent", "opaque", "pseudo-derived", and "orthographic" as shorthands for these four types of prime-target pairs. Below are listed examples of the four types of prime-target pairs.

(1) Transparent: gaufrette/GAUFRE "wafer/waffle".

(2) Opaque: fauvette/FAUVE "warbler/wildcat".

(3) Pseudo-derived: baguette/BAGUE "little stick/ring".

(4) Orthographic: abricot/ABRI "apricot/shelter".

In all pairs, the prime is the longest word and the target the shortest word. The 30 orthographic pairs of words cannot be segmented into morphemic units; in all cases, the prime is never a derived or pseudoderived form of the target. For example, in abricot/ABRI, -cot from abricot is not a suffix in French.

The first three types of pairs were matched for their surface morphological structure: for each transparent pair, there were one opaque pair and one pseudo-derived pair with the same surface morphological structure but not with the same diachronic and synchronic relationship. For example, the pairs plumeau/PLUME "feather duster/feather" (transparent), rideau/RIDE "curtain/wrinkle" (opaque) and pinceau/ PINCE "paintbrush/pliers" (pseudo-derived) all have the same structure, but whereas plumeau is etymologically and semantically related to plume, rideau is etymologically but not semantically related to ride, and pinceau is neither etymologically nor semantically related to pince. Within each triplet of prime-target pairs, primes and targets have the same grammatical category and the same orthographical overlap. In the transparent and opaque pairs, primes were well-formed derived words of French: their morphemic structure conformed to the word-formation rules of the language. In the pseudo-derived pairs, the primes could be interpreted as morphologically complex, that is, each prime could have been derived from its apparent base word in French. For instance, the suffix -ette is a nominal suffix that attaches to nouns or to verbs, producing $\left[[\mathrm{x}]_{\mathrm{N} / \mathrm{V}} \text { ette }\right]_{\mathrm{N}}$ words. The simple word baguette is a noun apparently derived from the nominal base word bague that could have been interpreted according to this morphological pattern. Thus, in each triplet of prime-target pairs (1-3), all primes share a common "suffix". This was intended to avoid the possibility that the potential differences between these three types of pairs be due to differences in the suffix involved.

When the prime was a verbal infinitive form and the prime a noun, the target never corresponded to a potential inflected verbal form. For example, in a pair like mouser/MOUSSE "to foam/foam, moss", mousse could be a noun ("foam") or an inflected form of the verb mousser (first 
and third person, singular, present, indicative). Such pairs were thus avoided. We instead only used pairs like traiter/TRAIT "to treat/stroke, line", where trait is not an inflected form of traiter.

Moreover, if the base word of the derivation was a verbal form, we used the "dictionary entry" form, that is, the infinitive form, instead of the actual verbal stem. In French, a semantically transparent derived word like fumoir is built on the verbal stem /fym/-the present indicative inflected form. The dictionary form (infinitive form) of this verb is fumer. In this respect, French differs from English, in which the dictionary entry form and the stem are identical most of the time. In a pair such as fumoir/ FUMER, the target is not as optimally embedded in the prime as in fumoir/FUME. We nevertheless decided that the most sensible option in such a case was to use the former pair because it simply might be disturbing for subjects to decide, in a lexical decision task, that fume is a word. Indeed, fume rarely occurs in isolation and requires being preceded by a subject, pronoun, or noun.

In order to ascertain the semantic relationship between primes and targets in the initial selection, we first used "Le Nouveau Petit Robert" dictionary (Rey-Debove \& Rey, 1993) with the following criteria: definitions of the derived transparent words had to include either their morphological base word, or the word(s) used in the definition of this base. Conversely, definitions of opaque and pseudo-derived words could not include their etymological or apparent base word, nor could they include the words used to define that "base".

The initial set of 120 prime-target pairs ( 30 pairs $\times 4$ pair-types) was then presented in print to 60 French-speaking subjects ${ }^{1}$ who rated the semantic relatedness between the members of each pair on a 1-4 scale from highly related to unrelated. We retained the transparent pairs that were rated below 1.5 (fairly highly related), and the opaque, pseudo-derived, and orthographic pairs that were rated above 3.5 (poorly related), thereby selecting 20 pairs for each type. Given the difficulty to find stimuli meeting the criteria described above, we could not match perfectly the frequencies (as found in the "Brulex" database; Content, Mousty, and Radeau, 1990) of the primes and of the targets between and within conditions. Each target was also associated with an orthographically and semantically unrelated control prime, which matched the related prime for frequency, number of syllables and grammatical category. The total number of test prime-target pairs thus

\footnotetext{
${ }^{1}$ We ran this pre-test with French and Canadian subjects (30 subjects each) to make sure that there was no dialectal difference between the French subjects of Experiment 1 and the French Canadian subjects of Experiment 2. There was no difference between the two groups as far as the selected items were concerned.
} 
amounted to $160=2 \times 20 \times 4$. Table 1 summarises the main characteristics of the related prime-targets that were used (see Appendix for the complete list of materials). The orthographic or phonemic overlap corresponds to the number of letters or phonemes, respectively, that are shared by the prime and the target of a prime-target pair.

The four types of prime-target pairs were balanced at best with respect to related prime frequency, target frequency, as well as to orthographic and phonemic overlap. As for subjective relatedness rating, "transparent" pairs were successfully contrasted against the other three types of pairs (mean 1.07 vs. 3.66, respectively), $F(1,76)=3379.8, p<.00001$. As a rule, the other comparisons revealed non-significant differences. However, there was a significant trend for more orthographic overlap with transparent than with non-transparent pairs (5.15 vs. 4.47 letters), $F(1,76)=8.46, p<.005$. A parallel trend for more phonemic overlap with transparent pairs, though, was not significant (3.45 vs. 3.07 phonemes). It is worth noting that there was a trend for differences in target frequencies: orthographic targets tended to be less frequent than pseudo-derived targets, $F(1,38)=3.20, p=.079$, or than opaque targets, $F(1,38)=2.35, p=.13$. These numerical differences should be kept in mind when discussing the results.

The set of 160 prime-target pairs was split into two lists in order to counterbalance prime-target relation (related vs. unrelated) between participants. For all the 80 target words appearing in one list, half of them associated with a related prime, and the other half were with an unrelated (control) prime. These prime-target associations were reversed in the other list. Each participant was assigned to one of the two lists

TABLE 1

Main characteristics of the related prime-target pairs according to the relation type

\begin{tabular}{lccccc}
\hline & \multicolumn{5}{c}{ Characteristics } \\
\cline { 2 - 6 } & $\begin{array}{c}\text { Prime } \\
\text { frequency } \\
\text { (per million) }\end{array}$ & $\begin{array}{c}\text { Target } \\
\text { frequency } \\
\text { (per million) }\end{array}$ & $\begin{array}{c}\text { Orthographic } \\
\text { overlap } \\
\text { (in number } \\
\text { of letters) }\end{array}$ & $\begin{array}{c}\text { Phonological } \\
\text { overlap } \\
\text { (in number of } \\
\text { phonemes) }\end{array}$ & $\begin{array}{c}\text { Relatedness } \\
\text { rating } \\
(1-4)\end{array}$ \\
\hline $\begin{array}{l}\text { Transparent } \\
\text { gaufrette/GAUFRE }\end{array}$ & 11.6 & 22.8 & 5.15 & 3.45 & 1.07 \\
$\begin{array}{l}\text { Opaque } \\
\text { vignette/VIGNE }\end{array}$ & 12.0 & 35.9 & 4.40 & 3.05 & 3.50 \\
$\begin{array}{l}\text { Pseudo-derived } \\
\text { baguette/BAGUE } \\
\begin{array}{l}\text { Orthographic } \\
\text { abricot/ABRI }\end{array}\end{array}$ & 20.8 & 41.6 & 4.60 & 3.00 & 3.69 \\
\hline
\end{tabular}


(hence, two groups of participants), and was thus presented with each target only once, either with a related or an unrelated prime.

In order to reduce the proportion of formally (morphologically or orthographically) related words, 20 pairs of semantically associated words (cf. the association norms by Ferrand \& Alario, 1998) and 20 pairs of unrelated words were added to each experimental list. Because each list thus contained 120 word target pairs, an equal number of nonword target pairs had to be constructed. Among these nonword target pairs, 60 were orthographically and semantically unrelated (comptoir "counter"/dirtée); 40 were orthographically and "morphologically" related (drapeau "flag"'/ drat, from drap "sheet, cloth"), and, finally, 20 were "semantically associated" (chemise "shirt"/beuton, from bouton "button"). All the nonword targets were created by changing one or two letters of an existing word, making sure that the result conformed to the phonotactic constraints of French. To summarise, each subject had to make a lexical decision on 240 targets, 120 of which were word targets and 120 nonword targets. The experimental session was preceded by a training session consisting of 20 trials.

Procedure. We used a masked priming procedure as in Forster and Davis (1984). For each trial, a pre-mask of hashmarks (\#\#\#\#\#\#\#\#) appeared in the middle of the screen for $500 \mathrm{~ms}$; the pre-mask was immediately followed by the prime, in lower case, displayed for $46 \mathrm{~ms}$ and then immediately masked by the target, in upper case; the target remained on the screen for $3000 \mathrm{~ms}$ or until a response was given. Reaction times were measured from the onset of the target display. Primes and targets were displayed with a 14 point Arial font, in white on a black background. The experiment was run on a PC-compatible microcomputer using DMDX software, with on-line randomisation of trial order. Responses were entered via a Logitech Wingman gamepad. Participants used their dominant hand for the "yes" (i.e., "word") response.

Participants first received oral instructions as to the task to perform. They were seated in front of a computer screen (about $50 \mathrm{~cm}$ from their eyes) in a quiet room. The presence of a visual prime was not mentioned. Participants were told that in each trial, a string of letters would appear on the screen and they would have to decide as quickly and accurately as possible whether the letter string was a French word or not. The total duration of the experiment was 12 minutes.

Participants. Forty-three students at Université René Descartes (France) participated in Experiment 1 for course credit or voluntarily. All the participants were native speakers of French and had normal or corrected-to-normal vision. Six participants were rejected because their error rate for test target words exceeded $10 \%$, which was considered too 
high (error rate averaged to $4.4 \%$ for the other participants). An additional participant was rejected because his "yes" response times were considered too long (above $900 \mathrm{~ms}$, as compared with a $640 \mathrm{~ms}$ average RT for the other participants). This left 36 participants evenly divided in two groups, that is, assigned to one of the two lists (see above).

\section{Results}

Four pairs were removed because of a high error rate (more than $40 \%$ ) on the target (targets ban, gent, gond, and rabot); three additional pairs were also removed (aiguille-AIGU, airelle-AIRE, tonnerre-TONNE) because they had been assigned to incorrect categories. We eventually retained 73 items for subsequent analyses (19 items each in the transparent, opaque, and pseudo-derived conditions, and 16 items in the orthographic condition). Note that the removal of these items did not change significantly the main characteristics shown in Table 1 . Only reaction times for correct "yes" responses shorter than $1500 \mathrm{~ms}$ were retained for RT analyses (outliers corresponded to $1.1 \%$ of the data).

The results are summarised in Table 2. The RT and error rate data were submitted to by-subject and by-item analyses of variance with the following main factors: priming relation (related vs. unrelated) and relation type (transparent, opaque, pseudo-derived, and orthographic). The structural factors list (items analyses) or assignment to list (subjects analyses) had no significant effect $(F s<1)$ and did not interact with the other factors. They will not be discussed further.

TABLE 2

Experiment 1: Average RT (ms) and errors rate according to relation type and to priming relation, and priming effect in ms. Standard deviations are shown in parentheses

\begin{tabular}{|c|c|c|c|c|c|c|}
\hline \multirow[b]{3}{*}{ Relation type } & & \multicolumn{5}{|c|}{ Priming relation } \\
\hline & & \multicolumn{2}{|c|}{ Unrelated } & \multicolumn{2}{|c|}{ Related } & \multirow[t]{2}{*}{ Difference } \\
\hline & & $R T$ & Errors & $R T$ & Errors & \\
\hline Transparent & gaufrette/GAUFRE & $\begin{array}{l}650 \\
(86)\end{array}$ & $3.48 \%$ & $\begin{array}{c}612 \\
(70)\end{array}$ & $1.45 \%$ & 38 \\
\hline Opaque & vignette/VIGNE & $\begin{array}{l}653 \\
(90)\end{array}$ & $2.03 \%$ & $\begin{array}{l}610 \\
(64)\end{array}$ & $1.69 \%$ & 43 \\
\hline Pseudo-derived & baguette/BAGUE & $\begin{array}{l}639 \\
(81)\end{array}$ & $4.04 \%$ & $\begin{array}{l}613 \\
(77)\end{array}$ & $3.85 \%$ & 26 \\
\hline Orthographic & abricot/ABRI & $\begin{array}{l}672 \\
(92)\end{array}$ & $7.58 \%$ & $\begin{array}{l}698 \\
(82)\end{array}$ & $11.42 \%$ & -26 \\
\hline
\end{tabular}


Response times. Priming relation had a significant effect overall, $F_{1}(1,34)=10.42, p=.002 ; F_{2}(1,69)=8.93, p<.005$. "Yes" responses to targets were faster when targets appeared after related than unrelated primes. Relation type also has a significant effect overall, $F_{1}(3,102)=$ $34.70, p<.001 ; F_{2}(3,69)=4.34, p<.01$, and significantly interacted with priming relation, $F_{1}(3,102)=6.46, p<.001 ; F_{2}(3,69)=7.30, p<.001$. This reflected different priming effects across relation types: whereas the orthographic overlap relation induced slower RTs for related than for unrelated trials, the reverse pattern held for the three other types of primetarget relation types. Indeed, planned comparisons revealed a significantly positive priming effect for the semantically transparent relations, $38 \mathrm{~ms}$ : $F_{1}(1,34)=9.88, p<.005 ; F_{2}(1,18)=16.82, p<.001$, for the semantically opaque relation, $43 \mathrm{~ms}: F_{1}(1,34)=15.97, p<.001 ; F_{2}(1,18)=9.32, p<$ .01 , as well as for the pseudo-derivation relation, $26 \mathrm{~ms}: F_{1}(1,34)=5.53, p$ $<.05 ; F_{2}(1,18)<4.41, p=.05$. In contrast, orthographic overlap induced a negative priming effect $(-26 \mathrm{~ms}),{ }^{2}$ which was marginally significant by subjects, $F_{1}(1,34)=2.87, p=.095$, and significant by items, $F_{2}(1,15)=$ $4.44, p=.05$. The raw priming effects (RT difference between the unrelated and related conditions) were submitted to further analyses of variance in order to compare them across relation types: the three types of relation that induced positive priming did not differ from each other (all $p$ s $<.29$ ) but each differed from the orthographic overlap relation (all $p \mathrm{~s}<$ $.02)$. This confirms that there were only two priming patterns: facilitation

\footnotetext{
${ }^{2}$ As pointed out above, the materials could not be ideally matched with respect to target frequencies. These frequencies were lower for orthographic pairs (although not significantly so). Because form priming could be more sensitive to target frequency than morphological priming, it could be the case that the trend towards inhibition we obtained for orthographic pairs was a reflex of target frequency differences. In other words, the contrast between orthographic and other pairs would not reflect a qualitative difference between form priming and morphological priming but, more prosaically, quantitative differences in target frequencies. Note that the difference in target frequency only holds for orthographic (20.1) vs. pseudoderived (41.6) and opaque (35.9) pairs, not transparent (22.8) pairs. Moreover, it is quite reasonable to assume truly morphological rather than merely formal priming in the latter pairs. If the account of form priming across the board (except for transparent pairs) with priming effect size modulated by target frequency is correct, we should find a positive correlation between priming effect size and target frequency for the three types of pairs involved, pooled together. Independently, RT for 'yes' responses in the unrelated condition should correlate negatively with target frequency: this would signal unbiased usual frequency effects. We therefore conducted the relevant correlation analyses. We found a general negative correlation between RT and target frequency, as expected, $r(52)=-.586, p<.0001$. (This shows that the observed behaviour for lexical decision in the unrelated condition did not depart from expected behaviour.) As for the size of the priming effect, we found a nonsignificant trend towards negative correlation with target frequency, $r(52)=-.182, p=.187$. This straightforwardly rules out any confound with target frequency in the observed pattern of data: that form priming was modulated by frequency in non-transparent pairs is thus not tenable.
} 
whenever the prime could be a morphologically derived form of the target vs. inhibition whenever the prime could not be a derived form of the target.

Error rates. The error data largely reflected the RT data, although priming relation was not significant overall (both $F \mathrm{~s}<1$ ). Relation type had an overall significant effect, $F_{1}(1,102)=21.11, p<.001, F_{2}(3,69)=$ $5.08, p=.003$. For the transparent, opaque, and pseudo-derived pairs, error rate was lower in the related condition compared with the unrelated condition, although this was a non-significant trend. In contrast, for orthographic pairs, error rate was higher in the related condition than in the unrelated condition (a $3.84 \%$ difference); yet this difference was only marginally significant, $F_{1}(1,34)=2.97, p=.09, F_{2}(1,15)=3.03, p=.099$.

\section{Discussion}

We obtained a significant facilitation in a masked priming paradigm for the three kinds of pairs that were "morphologically" related: a simple word was recognised faster if it was preceded by either a transparent, an opaque, or a pseudo-derived related word; in contrast, a simple word was recognised more slowly if it was preceded by a longer word that was only orthographically related to it. Those results show that in French, there is no effect of semantic opacity in masked priming, since both transparent and opaque pairs behave the same way, as in English or Hebrew. Pseudoderived pairs behave the same way as opaque pairs do, and not as orthographic controls. The marginal inhibition effect obtained for orthographic controls suggests that the effects for transparent, opaque, and pseudo-derived pairs are morphological in nature and not orthographic. $^{3}$ Similar results were reported by Giraudo and Grainger (2001) using words with a "pseudo-root" to prime a semantically transparent derived word. As we mentioned earlier, their "pseudo-root" primes are equivalent to our orthographic controls in the sense that they include a

\footnotetext{
${ }^{3}$ This was confirmed by an additional experiment using a $70 \mathrm{~ms}$ prime exposure time. The pattern of results was essentially the same as in Experiment 1, though somewhat less contrasted. The priming effects were $+38 \mathrm{~ms}$ (transparent pairs), $+16 \mathrm{~ms}$ (opaque pairs), $+34 \mathrm{~ms}$ (pseudo-derived pairs), and $-6 \mathrm{~ms}$ (orthographic controls). This less contrasted pattern was presumably due to the increased visibility of the prime: it is likely that some of the participants were often aware of the prime. As it seems, whether or not the prime is consciously perceived can be crucial for the nature of the priming effect. Badecker and Allen (2002) found that with a $63 \mathrm{~ms}$ prime duration, 12 subjects out of 64 reported they had often "seen" the prime: the priming effect for these 12 subjects drastically differed from that obtained for the other subjects who had not seen any prime at all (inhibition vs. facilitation, respectively).
} 
word, but not a suffixal ending. ${ }^{4}$ The simultaneous presence of a root and a suffix seems to be critical to obtain a facilitation effect in masked priming. We will come back to these results and their methodological and theoretical implications in the general discussion.

Before that, let us turn to the second experiment, in which we used a cross-modal priming procedure with the same materials. If French words are processed like English words, we should get a priming effect only for transparent pairs. Again, pseudo-derived pairs should be processed in the same way as opaque pairs.

\section{EXPERIMENT 2: AUDITORY-VISUAL CROSS-MODAL PRIMING}

\section{Method}

Materials and design. The materials and design in Experiment 2 were the same as in Experiment 1. The auditory primes were recorded on a digital tape recorder by a female native speaker of Canadian French, and then digitised and stored on computer disk. As in Experiment 1, the materials were split into two experimental lists, each assigned to one group of participants, so that a given participant was presented with each target only once, either with a related or with an unrelated prime. The experimental session was preceded by a training phase consisting of 20 trials.

Participants. Thirty-seven students at Université du Québec à Montréal (Canada) participated voluntarily in Experiment 2. All subjects were native speakers of French, had normal or corrected-to-normal vision and reported normal hearing. Four participants were rejected: two because their response times were too long (more than $900 \mathrm{~ms}$ in average), and two others because their error rate was too high (above 10\%). We were thus left with 17 participants in one group and 16 in the other group.

Procedure. We used a cross-modal priming procedure similar to that used by Marslen-Wilson et al. (1994). Each trial began with the $500 \mathrm{~ms}$ display of a visual fixation cross $(+)$ in the middle of the screen, immediately followed by the auditory prime. The visual target was

\footnotetext{
${ }^{4}$ But note that although Giraudo and Grainger's (2001) 'pseudo-root' primes were defined as monomorphemic words containing a sequence of letters that is the (actual) root of the target and no suffixal ending, the only example they give of their pseudo-root prime, laitue/ LAITIER, is polymorphemic. Laitue is an opaque word consisting of the root lait 'milk' and the suffix $-u[e]$, found in both adjectives and nouns such as barbu, chevelu, feuillu, joufflu, poilu, bossu, etc.
} 
displayed in the middle of the screen at the acoustic offset of the prime. The target disappeared after $1500 \mathrm{~ms}$, or as soon as a response button was pressed. Response times were measured from the onset of target display. The next trial was then initiated after a $750 \mathrm{~ms}$ delay. Targets appeared in black on a light-grey background in lower-case 14 point Arial font. The experiment was run on a PC-compatible microcomputer using DMDX software, and the participants heard the auditory primes through Sennheiser headphones at a comfortable listening level. The participants' task was to make a lexical decision to the visual target, using a two-button response device as in Experiment 1.

Participants first received oral instructions as to the task to perform. They were told that they would hear a word in the headphones and then see a string of letters in the middle of the screen; they would have to decide as quickly and accurately as possible whether the letter string was a word in French or not. The total duration of the experiment was 15 min.

\section{Results}

For the sake of comparison with Experiment 1, the seven items that had been excluded in Experiment 1 were also excluded from the analyses of Experiment 2. Only reaction times for correct "yes" responses shorter than $1500 \mathrm{~ms}$ were retained for RT analyses (outliers corresponded to $0.89 \%$ of the data). The results are summarised in Table 3. The RT and error rate data were submitted to the same kinds of analyses of variance as the corresponding data in Experiment 1.

TABLE 3

Experiment 2: Average RT (ms) and error rates according to relation type and to priming relation, and priming effect in $\mathrm{ms}$. Standard deviations are shown in parentheses

\begin{tabular}{|c|c|c|c|c|c|c|}
\hline \multirow[b]{3}{*}{ Relation type } & & \multicolumn{5}{|c|}{ Priming relation } \\
\hline & & \multicolumn{2}{|c|}{ Unrelated } & \multicolumn{2}{|c|}{ Related } & \multirow[t]{2}{*}{ Difference } \\
\hline & & $R T$ & Errors & $R T$ & Errors & \\
\hline Transparent & gaufrette/GAUFRE & $\begin{array}{l}666 \\
(104)\end{array}$ & $3.88 \%$ & $\begin{array}{l}628 \\
(93)\end{array}$ & $0.62 \%$ & 38 \\
\hline Opaque & vignette/VIGNE & $\begin{array}{l}642 \\
(82)\end{array}$ & $(3.66 \%)$ & $\begin{array}{c}651 \\
(105)\end{array}$ & $1.53 \%$ & -9 \\
\hline Pseudo-derived & baguette/BAGUE & $\begin{array}{l}651 \\
(89)\end{array}$ & $(4.57 \%)$ & $\begin{array}{c}662 \\
(111)\end{array}$ & $3.23 \%$ & -11 \\
\hline Orthographic & vendredi/VENDRE & $\begin{array}{l}693 \\
(120)\end{array}$ & $6.35 \%$ & $\begin{array}{c}705 \\
(109)\end{array}$ & $5.32 \%$ & -12 \\
\hline
\end{tabular}


Responses times. Priming relation had no significant effect overall (both $F$ s $<1)$. However, only the transparent pairs induced a significant $38 \mathrm{~ms}$ priming effect, $F_{1}(1,31)=14.04, p<.001 ; F_{2}(1,18)=5.57, p<.05$. There was no significant priming effect for the three other relation types: the negative numerical values reported in Table 3 do not correspond to significant inhibitory effects.

Error rate. The error rate data roughly paralleled the RT data. Planned comparisons showed that only transparent pairs induced a substantial diminution of the error rate of about $3.3 \%$. Priming relation had a significant effect only for these pairs, and only in the by-subject analysis, $F_{1}(1,32)=11.54, p<.001 ; F_{2}(1,18)=2.91, p=.102$. The numerical diminution of error rates in the related pairs for each of the three other relation types (averaging to $1.2 \%$ ) did not reach significance.

\section{Discussion}

The same material as in Experiment 1 presented in auditory-visual crossmodal priming led to completely different results: only semantically transparent words primed their base word significantly, while no significant priming effect was found for the opaque, pseudo-derived and orthographic pairs. It seems that when the prime is auditory and consciously perceived, semantic transparency has a more central role to play in morphological priming. These results also confirm that pseudo-derived and opaque words are processed in the same manner because they yielded the same priming effect. Our results are thus consistent with those obtained by MarslenWilson et al. (1994) in English. They confirm the central role of semantic transparency in the cross-modal paradigm for languages with concatenative morphology. As expected, the formal morphological properties of the prime were not sufficient to produce priming, contrary to Arabic or Hebrew (Boudelaa \& Marslen-Wilson, 2000, 2001; Frost et al., 2000b).

\section{GENERAL DISCUSSION}

We compared priming effects for three types of prime-target pairs in which the prime was "morphologically" related to the target at the surface level and for one type of pair in which the prime was only orthographically related to the target. The morphologically related pairs were either semantically transparent, semantically opaque or pseudo-derived. The pattern of results was quite different depending on the mode of presentation of the stimuli. In visual masked priming, facilitation was obtained for the three types of morphological pairs (transparent, opaque, and pseudo-derived), whereas inhibition was obtained for the orthographic 
pairs. In auditory-visual cross-modal priming, only semantically transparent pairs produced facilitation. In the two experiments, the same priming effect was obtained for opaque and pseudo-derived pairs. We had expected similar effects for these two types of pairs, based on their synchronically equivalent status and structure.

The results of Experiment 1 show that there is a clear effect of the surface morphological structure of the prime in masked priming. This morphological effect is not due to mere orthographic overlap between the prime and the target because the orthographic controls produced inhibition. Put another way, this effect cannot be explained by the embedding of a word at the beginning of the prime (see Drews and Zwitserlood (1995) for similar orthographic inhibitory effects in Dutch; also see Pastizzo and Feldman (2002) in English). Importantly, our results show that strict criteria must be used to select appropriate orthographic controls when working with very short prime duration: absence of etymological relationship is not a sufficient criterion; words also must not be made of smaller morphemic units (which is precisely the case in pseudo-derived words).

Our results in masked priming revive, in a way, the old debate initiated by Taft and Forster (1975) about a prelexical affix-stripping process. According to these authors, the affix of an affixed word must be stripped off for lexical access to be successful. An automatic decomposition process is necessary to isolate the stem which constitutes the lexical entry of affixed words. Our results suggest that in masked conditions a decomposition process takes place, inducing activation of the corresponding morphemic or pseudo-morphemic constituents. If this is actually the case, then the observed priming effect is a consequence of the decomposition process and not the reflection of a relationship between the prime and the target in the mental lexicon, as is often proposed in the literature to explain morphological priming effects.

For example, Marslen-Wilson et al. (1994) propose a model in which the basic unit in the lexicon is the morpheme. When processing words, there is a direct mapping between the input and the content of the lexicon. This type of model would account for the results we obtained in cross-modal priming (Experiment 2), but it would not explain why, in the visual masked priming condition, the processing system tries to map baguette on bague and -ette instead of directly mapping it on baguette. A word like baguette must have its own lexical representation because its meaning is utterly unpredictable given its surface morphological structure. Moreover, on the view defended by Marslen-Wilson et al. (1994), baguette should not be related to the morphological family of bague because they assumed that opaque words-hence, pseudo-derived words even less so-are not related to their morphological family in the lexicon. However, pseudo-derived 
words like baguette did prime their apparent base in the masked priming condition. Opaque and pseudo-derived words are thus confusing for the processing system: They may induce formal decomposition, but they do not have compositional meaning.

Would a connectionist account of derivational morphology be more successful (Plaut \& Gonnerman, 2000; Seidenberg \& Gonnerman, 2000)? According to these models, the lexical representations correspond to patterns of activation across phonological, orthographic and semantic units. Morphemes are not directly represented. Rather, they are abstract regularities that may emerge in mapping between different types of units. In such models, an inter-level of hidden units registers convergences between codes and somehow captures statistical regularities in the lexicon such as morphemes, but does not represent them in a direct manner. Morphology in this context may thus be regarded as nothing more than a consequence of a regular mapping between form and meaning.

This type of model predicts that when semantic overlap is held constant, there should be a graded effect of formal overlap: the more two words are formally related, the more priming should be observed in a priming paradigm sensitive to formal overlap. Conversely, when formal overlap is held constant, there should be a graded effect of semantic overlap: the more two words are semantically related, the more they should prime each other. Gonnerman (1999) reported results consistent with these predictions, using a cross-modal paradigm. Our cross-modal priming results (Experiment 2) are consistent with these predictions in the sense that all four types of pairs had a constant orthographical overlap, and only the transparent pairs produced significant priming.

However, a problem arises when we look at the results of Experiment 1: formal overlap is, again, held constant for all four types of pairs. In particular, pseudo-derived pairs and orthographic pairs have the same formal overlap and both entertain no etymological and no semantic relationship. Yet, we found different priming patterns for these two types of pairs: facilitation for pseudo-derived words, and inhibition with orthographic controls. In the same vein, we should expect a drastic difference between transparent words, which are strongly semantically related, and opaque or pseudo-derived words, which are not, but this was not found. In the visual masking condition, semantic relationship did not modulate facilitation, and word recognition seemed to be blind to the semantic properties of the prime. A possible interpretation within the connectionist framework would propose that morphemes-roots or affixes-correspond to statistical regularities in form and meaning associations, and that affixes, in particular, are more salient because they are more likely to develop a consistent form-meaning mapping than nonaffixal endings (see Rastle et al., 2000, for a similar argument). 
We favour another interpretation of the data. The results of Experiment 1 suggest that, in the early stages of processing, an automatic process of morphemic decomposition is triggered by words that are morphologically complex with respect to their surface structure. Only if a word is truly and synchronically morphologically complex, that is, if its morphemic composition is semantically transparent, then morphemic decomposition proves useful and the resulting morphemic units can remain activated. In the cross-modal priming experiment, such long-lasting activation was observed for transparent primes. In contrast, for semantically opaque or for pseudo-derived word primes, the decomposition process was of no further use and, presumably, the activation of the morphemic units it produced quickly faded away, as is suggested by the absence of any residual priming effect with such primes in the cross-modal experiment.

The data of Experiment 1 are not compatible with the model of supralexical morphology as offered by Giraudo and Grainger (2001). According to this model, morphemes are activated after a whole word lexical representation has been activated. This model was proposed in part because, in several experiments, "pseudo-root" primes failed to induce significant priming effects. Giraudo and Grainger reasoned that sublexical morphemic analysis entails that the morphemic representation of a root be activated every time the sequence of letters for that morpheme is encountered. Their results, and ours as well for orthographic controls, show that this version of the "sublexical hypothesis" is not correct. We propose instead a prelexical decomposition process which, crucially, is sensitive to the simultaneous presence of a root and of an affix, that is, which is potentially triggered by surface level morphology.

Our interpretation of the masked priming results is in line with the studies on Hebrew by Frost and colleagues. First, Frost et al. (1997) demonstrated that two words sharing the same root morpheme prime each other, whether they share the same meaning or not. Deutsch, Frost, and Forster (1998) found priming not only between two words that share the same root, but also between two words that share the same verbal pattern (and not the same root). Second, and more relevant to the point we make, Frost, Deutsch, and Forster (2000a) reported masked priming experiments with a special category of Hebrew verbs: those with "weak roots", that is, roots that surface as incomplete in some inflected forms (e.g., the triconsonantal root $n p l$ surfaces as $p l$ in the weak verb hpyl "he overthrew"). When using these weak verbs (as primes or as targets), they failed to reproduce the priming effect previously established with verbal patterns. However, when the missing part of the weak root is complemented with a dummy consonant, the usual verbal pattern priming effect re-emerges. Frost et al. (2000a) interpreted their results as evidence for a blind morphemic decomposition process that operates for words that 
fit in an appropriate surface morphemic pattern. Weak verbs are idiosyncratic in nature and for this reason must be listed as separate, undecomposed words in the lexicon. Yet, provided they are appropriately complemented so that they fit in the usual triconsonantal root verb pattern, they still may be analysed into morphemes. Thus, the sole surface morphology can trigger morphemic decomposition in Hebrew and this is also what we find for pseudo-derived words in French. But in Hebrew, virtually all the words are morphologically complex and this might require that morphemic analysis is routinely and automatically performed by the users of this language.

In French, however, morphemic composition is likely less salient than in Hebrew. This is shown by the failure to obtain facilitation effects in cross-modal priming with opaque and pseudo-derived pairs. In Hebrew, opaque words produce significant priming effects even in the cross-modal priming paradigm (Frost et al., 2000b). Yet, in a way, morphemic composition is a rather salient characteristic of French, and this might explain why we find morphological effects in masked priming even with pseudo-derived words although they are not etymologically related. According to Rey-Debove (1984), about $70 \%$ of French words are morphologically complex and have a compositional meaning. For this reason, it may be strategically efficient for the processing system to try out a decomposition on every word that looks complex, even if this occasionally leads to an incorrect analysis.

As noted previously, the difference between pseudo-derived and orthographic primes is the pseudo-suffixal status of their ending. We do not know at this time whether the morphemic decomposition of the pseudo-derived words is triggered by the sole presence of a suffix or by the simultaneous presence of a suffix and a potential base word. For instance, we may surmise that the pseudo-suffix -ette of silhouette is sufficient to launch decomposition. Yet, because no approximation of silhou can be found in the lexicon, the decomposition process is doomed to fail and to be abandoned. Further research would be necessary to address the issue of how surface-structure morphemic decomposition is triggered. Namely, is it mainly due to the special salience of a suffix form?

A related issue is the role of morpheme productivity in processing complex words. Would "blind" morphological decomposition be sensitive to the productivity and the frequency (types and tokens) of the affix involved? Blind decomposition might also depend on the particulars of language-specific morphology: it perhaps operates only for those languages with rich morphological systems, not for languages whose morphology is considered as "poor". Indeed, Marslen-Wilson (2001) proposed that there exists some sort of "morphological continuum" with, at one end, languages with limited morphological structures (such as Mandarin Chinese) and, at 
the other end, languages in which morphology is a very productive and perhaps mandatory structuring factor, such as Hebrew or Arabic. In between, languages such as French may probably be closer to Hebrew than to Chinese with respect to morphology. In these languages, morphological priming without true morphological relationship, as found in the present study, would be observed.

Manuscript received March 2002

Revised manuscript received October 2002

\section{REFERENCES}

Allen, M., \& Badecker, W. (1999). Stem homograph inhibition and stem allomorphy: Representing and processing inflected forms in a multi-level lexical system. Journal of Memory and Language, 41, 105-123.

Badecker, W., \& Allen, M. (2002). Morphological parsing and the perception of lexical identity: A masked priming study of stem homographs. Journal of Memory and Language, 47 (1), 125-144.

Bertram, R., Laine, M., Baayen, R.H., Schreuder, R., \& Hyönä, J. (2000a). Affixal homonymy triggers full-form storage, even with inflected words, even in a morphologically rich language. Cognition, 74, B13-B25.

Bertram, S., Laine, M., \& Karvinen, K. (1999). The interplay of words formation type, affixal homonymy, and productivity in lexical processing: Evidence from a morphologically rich language. Journal of Psycholinguistic Research, 28, 213-226.

Bertram, R., Schreuder, R., \& Baayen, R. H. (2000b). The balance storage and computation in morphological processing: The role of word formation type, affixal homonymy, and productivity. Journal of Experimental Psychology: Learning, Memory, and Cognition, 26, 489-511.

Boudelaa, S., \& Marslen-Wilson, W.D. (2000). Non-concatenative morphemes in language processing: Evidence from Modern Standard Arabic. Proceedings of SWAP, Nijmegen, MPI for Psycholinguistics, 23-26.

Boudelaa, S., \& Marslen-Wilson, W.D. (2001). Morphological units in the Arabic mental lexicon. Cognition, 81 (1), 65-92.

Burani, C., \& Caramazza, A. (1987). Representation and processing of derived words. Language and Cognitive Processes, 2 (3/4), 217-227.

Burani, C., Dovetto, F.M., Thornton, A.M., \& Laudanna, A. (1997). Accessing and naming suffixed pseudo-words. In G. Booij \& J. van Marle (Eds), Yearbook of Morphology 1996 (pp. 55-72). Netherlands: Kluwer Academic Publishers.

Colé, P., Beauvillain, C., \& Segui, J. (1989). On the representation and processing of prefixed and suffixed derived words: A differential frequency effect. Journal of Memory and Language, 28, 1-13.

Content, A., Mousty, P., \& Radeau, M. (1990). BRULEX: Une base de données lexicales informatisée pour le français écrit et parlé. L'Année Psychologique, 90, 551-566.

Deutsch, A., Frost, R., \& Forster, K.I. (1998). Verbs and nouns are organized and accessed differently in the mental lexicon: Evidence from Hebrew. Journal of Experimental Psychology: Learning, Memory, and Cognition, 24, 1238-1255.

Drews, E., \& Zwitserlood, P. (1995). Morphological and orthographic similarity in visual word recognition. Journal of Experimental Psychology: Human Perception and Performance, 21 (5), 1098-1116. 
Feldman, L.B., \& Soltano, E.G. (1999). Morphological priming: The role of prime duration, semantic transparency, and affix position. Brain and Language, 68, 33-39.

Ferrand, L., \& Alario, F.-X. (1998). Normes d'associations verbales pour 366 noms d'objets concrets. L'Année Psychologique, 98, 689-739.

Forster, K.I., \& Davis, C. (1984). Repetition priming and frequency attenuation in lexical access. Journal of Experimental Psychology: Learning, Memory, and Cognition, 10, 680698.

Frost, R., Deutsch, A., \& Forster, K.I. (2000a). Decomposing morphologically complex words in an nonlinear morphology. Journal of Experimental Psychology: Learning, Memory, and Cognition, 26, 751-765.

Frost, R., Deutsch, A., Gilboa, O., Tannenbaum, M., \& Marslen-Wilson, W.D. (2000b). Morphological priming: dissociation of phonological, semantic, and morphological factors. Memory and Cognition, 28 (8), 1277-1288.

Frost, R., Forster, K.I., \& Deutsch, A. (1997). What can we learn from the morphology of Hebrew? A masked-priming investigation of morphological representation. Journal of Experimental Psychology: Learning, Memory, and Cognition, 23 (4), 829-856.

Giraudo, H., \& Grainger, J. (2001). Priming complex words: Evidence for supralexical representation of morphology. Psychonomic Bulletin and Review, 8 (1), 127-131.

Giraudo, H., \& Grainger, J. (in press). On the role of derivational affixes in recognizing complex words: Evidence from masked priming. In H. Baayen (Ed.), Aspects of morphological processing. New York: Mouton de Gruyter.

Gonnerman, L.M. (1999). Morphology and the lexicon: Exploring the semantic-phonology interface. Unpublished doctoral dissertation, University of Southern California.

Grainger, J., Colé, P., \& Segui, J. (1991). Masked morphological priming in visual word recognition. Journal of Memory and Language, 30, 370-384.

Laudanna, A., Badecker, W., \& Caramazza, A. (1989). Priming homographic stems. Journal of Memory and Language, 28, 531-546.

Laudanna, A., Badecker, W., \& Caramazza, A. (1992). Processing inflectional and derivational morphology. Journal of Memory and Language, 31, 333-348.

Marslen-Wilson, W.D. (2001). Access to lexical representations: Cross-linguistic issues. Language and Cognitive Processes, 16 (5/6), 699-708.

Marslen-Wilson, W.D., Tyler, L.K., Waksler, R., \& Older, L. (1994). Morphology and meaning in the English mental lexicon. Psychological Review, 101 (1), 3-33.

McQueen, J. M., \& Cutler, A. (1998). Morphology in word recognition. In A. Spencer \& A.M. Zwicky (Eds.), Handbook of Morphology (pp. 406-427). Oxford: Blackwell Publishers.

Meunier, F., \& Segui, J. (1999). Morphological priming effect: The role of surface frequency. Brain and Language, 68, 54-60.

Pastizzo, M.J., \& Feldman, L.B. (2002). Discrepancies between orthographic and unrelated baselines in masked priming undermine a decompositional account of morphological facilitation. Journal of Experimental Psychology: Learning, Memory, and Cognition, 28 (1), 244-249.

Plaut, D.C., \& Gonnerman, L.G. (2000). Are non-semantic morphological effects incompatible with a distributed connectionist approach to lexical processing? Language and Cognitive Processes, 15 (4/5), 445-485.

Rastle, K., Davis, M.H., Marslen-Wilson, W.D., \& Tyler, L.K. (2000). Morphological and semantic effects in visual word recognition: A time-course study. Language and Cognitive Processes, 15 (4/5), 507-537.

Rey-Debove, J. (1984). Le domaine de la morphologie lexicale. Cahiers de Lexicologie, 45, $3-$ 19.

Rey-Debove, J., \& Rey, A. (1993). Le Nouveau Petit Robert. Paris: Editions Le Robert. 
Seidenberg, M.S., \& Gonnerman, L.M. (2000). Explaining derivational morphology as the convergence of codes. Trends in Cognitive Sciences, 4 (9), 353-361.

Taft, M. (1979). Recognition of affixed words and the word frequency effect. Memory and Cognition, 7, 263-272.

Taft, M., \& Forster, K.I. (1975). Lexical storage and retrieval of prefixed words. Journal of Verbal Learning and Verbal Behavior, 15, 638-647.

\section{APPENDIX}

\section{Material of Experiments 1 and 2}

\begin{tabular}{|c|c|c|c|c|}
\hline & Transparent & Opaque & Pseudo-derived & Orthographic \\
\hline 1. & sauter/SAUT & rater/RAT & traiter/TRAIT & sagac \\
\hline 2. & souhaiter/SOUHAIT & gigoter/GIGOT & repasser/REPAS & /BULLE \\
\hline 3. & foudroyer/FOUDRE & chatoyer/CHAT & soudoyer/SOUDE & aveugle/AVEU \\
\hline 4. & savonnette/SAVON & lunette/LUNE & baguette/BAGUE & abricot/ABRI \\
\hline 5. & gaufrette/GAUFRE & vignette/VIGNE & banquette/BANQUE & verveine/VERVE \\
\hline 6. & pochette/POCHE & fauvette/FAUVE & carpette/CARPE & troupe/TROU \\
\hline 7. & clochette/CLOCHE & toilette/TOILE & chouette/CHOU & cerfeuil/CERF \\
\hline 8. & coffret/COFFRE & fleuret/FLEUR & fouet/FOU & boucan/BOUC \\
\hline 9. & coussinet/COUSSIN & briquet/BRIQUE & brochet/BROCHE & auberge/AUBE \\
\hline 10. & rondelle/ROND & dentelle/DENT & flanelle/FLAN & requinquer/REQUIN \\
\hline 11. & plumeau/PLUME & rideau/RIDE & pinceau/PINCE & vendredi/VENDRE \\
\hline 12. & douanier/DOUANE & pionnier/PION & papier/PAPE & tracteur/TRAC \\
\hline 13. & fumoir/FUMER & couloir/COULER & bougeoir/BOUGER & corneille/CORNE \\
\hline 14. & chauffage/CHAUFFER & ravage/RAVIR & sauvage/SAUVER & camphre/CAMP \\
\hline 15. & palpable/PALPER & minable/MINER & coupable/COUPER & seringue/SERIN \\
\hline 16. & sonnette/SONNER & épuisette/ÉPUISER & moquette/MOQUER & écureuil/ÉCU \\
\hline 17. & maillon/MAILLE & boulon/BOULE & papillon/PAPILLE & *gentil/GENT \\
\hline 18. & *raboter/RABOT & saboter/SABOT & louper/LOUP & *aiguille/AIGU \\
\hline 19. & poutrelle/POUTRE & cannelle/CANNE & *airelle/AIRE & *gondole/GOND \\
\hline 20. & verbal/VERBE & *banal/BAN & cordial/CORDE & *tonnerre/TONNE \\
\hline
\end{tabular}

* The pairs marked with an asterisk were removed from the analysis. 